The author made this article openly available online. Please tell us how this access affects you. Your story matters.

Anderson, Stephen R. and Lightfoot, David W. (2006). Biology and Language: A Response to Everett (2005). Journal of Linguistics, 42, pp 377-383.

doi: $10.1017 / \mathrm{S} 002222670600394 \mathrm{X}$

Collection Permanent Link: hdl.handle.net/10822/557390

(C) 2006 Cambridge University Press

This material is made available online with the permission of the author, and in accordance with publisher policies. No further reproduction or distribution of this copy is permitted by electronic transmission or any other means. 


\title{
Biology and Language: A response to Everett (2005)
}

\author{
Stephen R. Anderson \\ Yale University \\ David W. Lightfoot \\ National Science Foundation
}

In a recent review article in this journal, Everett (2005) finds our book Anderson \& Lightfoot 2002 (as well as Givon 2002) seriously lacking and unpersuasive in the case it attempts to make for the importance of an understanding of the human language faculty as an aspect of our species' biology. Negative reviews are of course a feature of academic life, but Everett's piece exhibits enough misconceptions and misrepresentations, both of our work and of the nature of biology, to warrant a response.

We note that while Everett backhandedly compliments us for a number of carefully argued analyses, he simultaneously asserts (without discussion) that these are artificially restricted and do not bear the weight of our conclusions. A striking feature of his review is that he discusses and criticizes the analyses and views of others, rather than those presented in the book under review.

His summary of our book deals with each chapter in a summary of a few lines (p. 160) - his chapter-by-chapter summary of Givón's book is much more detailed - and does not engage most of what we had to say. For instance, he laments the fact our book contains "no biological discussion of any depth," although our chapter 10, entitled 'The organic basis of language,' attempts a survey of the literature bearing on the relation of the language faculty to specific tissue and its observable properties, intended for the use of our target audience of scientifically literate non-linguists. It is true that (like Givón, and Everett) neither of us "has any serious credentials in neurophysiology," but while we make no claim to originality in this chapter, we do feel it makes serious contact with the existing literature of the field. Everett devotes two lines to that chapter.

\section{The Nature of the Language Organ}

Our book is subtitled 'Linguistics as cognitive physiology,' and one of our major goals (p.ix-x) was to ask for a broader view of physiology than one that is limited to anatomy and the products of current imaging technology. Our argument was that we could usefully think about the functions of the brain that clearly stem from its biology. And that, in turn, would entail conducting our linguistic descriptions and analyses in particular ways, for example, defining and tackling poverty-of-stimulus problems head-on. 
Everett begins his substantive discussion of our book by asking what we mean by a language "organ." Unfortunately, he immediately demonstrates his lack of understanding of our project by treating this as a matter of anatomy, the structure of biological tissue, while we take pains from the outset, as just noted, to make it clear that we are dealing with the study of the function of tissue, or physiology. The human nervous system may or may not contain tissue specifically and exclusively dedicated to the faculty of language (we argue, in fact, that this is at most marginally true), but that does not in itself bear on the question of whether there is a distinguishable set of functions of brain tissue that serves this purpose. It is true that the usual sense of the word 'physiology' has excluded by fiat "the phenomena of mental life," but we argue that this restriction is arbitrary and unwarranted, and that furthermore it reflects misconceptions based on long-outdated notions of mindbody distinctions.

He suggests that the book confounds a number of possibly unrelated notions concerning the 'language organ,' which we invoke (incorrectly) as if they were interchangeable. One of these can be disposed of immediately as a misinterpretation. Everett notes (p. 161) that we sometimes speak of e.g. a "focus on language organs" (plural), and speculates as to whether we intend to treat various subcomponents of the language faculty as the responsibility of distinct "organs." We may well have been responsible for this confusion, since we did not explicitly explain our usage here. But the use of the plural in such expressions is in no way intended to imply a plurality of language organs of the sort Everett imagines. Rather, we meant simply that every individual speaker, by virtue of being human and having knowledge of a language, has a 'language organ' that realizes and subserves that knowledge. These may in fact differ among individuals in small but subtle ways, without the differences necessarily being obvious or a significant obstacle to communication. The study of language across a speech community thus involves the study of the language organs of its constituent speakers.

He then proceeds to analyze our claim that a person's knowledge of language is what we mean by her language organ. He points out that in this formulation, we do not distinguish between the knowledge eventually attributable to a fluent speaker and the biologically determined conditions that make it possible for that knowledge to be attained: the "initial state" of the learner, including the modes of inference that will be brought to bear on observed linguistic data in the course of arriving at a complete grammar. This is a useful and rather traditional distinction, and one worth pointing out, of course. In fact, we emphasize this distinction at several points, particularly in chapters 2, 3, 8 and 9, where we distinguish between the initial state, which we call UG or the linguistic genotype, and the mature state, which we call a grammar or the linguistic phenotype, and chapter 9, entitled "'Growing" a language,' focuses on how children develop from the initial state to a mature state. The remainder of Everett's discussion of the concept of a 'language organ' is directed (like several other passages in the article) at remarks of Chomsky's with which he disagrees, and whose relevance to anything we actually say is unclear. 


\section{The Poverty of the Stimulus}

A central feature of claims that language must involve an innate capacity deriving from the biology of our species has long been arguments deriving from the fact that languagelearners come to know things that they could not have derived from mere induction on the data available to them during the course of acquisition, arguments from "the poverty of the stimulus" (see for example Lightfoot 1999). In chapter 2 of our book, we offer two arguments of this sort, from the development of the use of contracted auxiliary forms in English and from the use of pronouns to refer to individuals represented by other expressions within the same syntactic domain. Chapter 3 is an extended discussion of the way poverty-of-stimulus logic shapes syntactic analysis. Other analyses presented in later chapters also serve to establish the same basic point.

Mysteriously, Everett chooses (pp. 162ff.) not to engage our analyses here, but rather to discuss a completely different example of such an argument, that involving the formation of yes-no questions by inversion of the principal auxiliary verb of the main clause. While this may be, as he says, "an old standby paradigm of Chomsky's," it is not something we dealt with or offered as evidence in our book, so it is not clear why he should discuss it. Discussion of this argument by, e.g., Pullum \& Scholz 2002, has at least called into question the extent to which evidence for the correct analysis of inversion here is not present in the data available to the child (though one might legitimately take issue with the extent to which a study of the Wall Street Journal corpus bears directly on the nature of those data). Everett argues that a consideration of information available to children from intonation and phrasing in speech shows that the relevant data are in fact available to the language learner, and criticizes Chomsky and us for failing to take intonational phenomena into account.

Obviously, any particular instance of an argument from "the poverty of the stimulus" is an empirical one, and as such subject to disconfirmation. But all such arguments are not indissolubly linked. Even if the standard account of yes-no question formation ultimately fails to provide support of the intended kind for an innate language capacity in the child, a criticism of our book ought to be based on a refutation of one or more of the analyses presented there, such as the account we offer of why contracted auxiliaries are used correctly in the apparent absence of at least some relevant evidence (an account extended and placed in a larger context, including prosodic factors, in Anderson 2005). Everett insinuates that intonational phenomena might have some bearing on the analysis, but gives no details or counter-analysis. We see no reason, therefore, to believe that his remarks bear on the general probative value of arguments from the poverty of the stimulus, and continue to maintain that these furnish important evidence in favor of an innate language faculty.

\section{Language and Evolution}

Puzzlingly, Everett seems both to take us to task for ignoring the role of studies of evolution in understanding the nature of language (pp. 171f.) and also to attribute to us (p. 
159) a specific view of how language evolved, apparently by association with the views of Chomsky on this subject.

In fact, however, we took no position at all in the book under review on the nature of the evolution of language, and did not discuss the matter. This was not because we were unacquainted with the relevant literature; in fact, we have both written about these issues in some detail (Lightfoot 1999, chapter 9; Anderson, in press). Rather, we feel that, at least in the present state of understanding of these matters, results from that field cannot teach us things about the nature of the language faculty. Since language is notoriously a phenomenon that leaves no traces in the fossil record for us to examine, accounts of its evolution largely have the character of "Just-So" stories of how this might have occurred. Some of these are more plausible than others, but none have the status of established scientific result that would serve to constrain our picture of the Language Organ. We may hope that evolutionary study may someday achieve a status that would alter this, but to date it does not seem to have done so. For the present, evolutionary concerns play no useful role in the kind of introductory treatment of language organs that we offered, in our view.

If Everett actually wishes to take issue with Chomsky's position, we invite him first to understand it (by consulting, for example, Hauser, Chomsky \& Fitch 2002, Fitch, Hauser \& Chomsky 2005) and then to join the queue of those wishing to disagree with it (including Pinker \& Jackendoff 2005 and many others). The Creationist image of both Chomsky's and our views that he attempts to invoke (p.159) might have a place in evolutionary discussion, though it has nothing to do with our claim (and Chomsky's) that the language faculty is an aspect of our biology which is unique to our species. Asserting that language as we find it in Homo sapiens is a species-specific capacity has no more "Catastrophist" a character (in Everett's sensationalist formulation) than the claim that echolocation is a species-specific capacity of bats.

\section{Linguistics and Biology}

Everett asserts that our characterization of much contemporary linguistics as a "biological" science is misconceived, apparently because it does not focus on the analysis of the properties of specific tissue. His support for this comes largely from references to the entertainingly caustic comments of Postal (2004) - not himself a noted biologist directed at remarks of Chomsky's about the biological significance of the study of language; as well as from critical commentary in Pulvermüller 2002 addressed to some studies of apparent neurophysiological correlates of syntactic constructs. The view of "Biology" thereby endorsed by Everett seems to us to be excessively restrictive, limiting biological studies to the sort of thing typified by high school classes devoted to the cutting up of frogs. Similarly, the view that if linguistics were as we claim, syntactic trees should be visible in CAT scans, asserted in Everett 2001, seems to reflect more on the adequacy of current brain imaging techniques than it does on the nature of language. 
Investigators have sought for a very long time to understand how the functions of an organism follow from its species-specific biology, and that work was part of the "grand synthesis" of biology at the beginning of the twentieth century. Indeed, that was the importance of Gregor Mendel's work on varieties of pea-plants, and modern linguists whose work we describe often see themselves as doing a kind of Mendelian genetics, teasing out properties that seem not to be learnable from the environment and which must be provided internally in some fashion, doing so by constructing poverty-of-stimulus problems in ways analogous to the Mendel's methods (Lightfoot 1999).

More recently, biologists have taken it as part of their task to understand the ways in which the structure of an organism's cognitive capacities are characteristic of its species and thus determined by its species-specific biology. For example, one of us satisfied the general education requirement in biology at the University of Chicago with a course in "The Biology of Behavior," a course whose content included (mutatis mutandis) many of the same research questions and specific animal models that figure currently in the course he currently offers on "Communication and Language Abilities in Animals" at Yale. The notion that scholars such as Lorenz, Tinbergen, von Frisch and others were not biologists because they spent insufficient time at the dissecting table or because their proposals cannot be confirmed by current brain imaging studies seems laughable ... and clearly not the view of the Nobel Prize committee that honored them with the prize they shared in 1973.

Indeed, much of the content of our book was developed in courses at The Johns Hopkins University - no naïf with respect to the nature of biology - where the Department of Cognitive Science originated within the Division of Biological Sciences. The initial impetus for the book was furnished by an article (Anderson \& Lightfoot 1999) explicitly requested by the editor of The Annual Review of Physiology. While that article may not have resulted in the conversion of many professional physiologists into linguists, reactions to it (as reported to us by the editor and confirmed by the number of reprint requests) do not suggest that many of them felt its appearance in that journal was inappropriate.

The study of the structure of species-specific cognitive organization clearly forms a part of biology regardless of whether that organization can be attributed to uniquely dedicated tissue. Its study in non-human animals has been largely limited to the analysis of externally realized behavior, not because that behavior was in and of itself the object of inquiry, but rather because the behavior resulting from cognitive processes is effectively the only evidence available in non-humans for their nature. The restriction of attention in such studies to behavior was, of course, characteristic of the "Behaviorist" school, but ever since the appearance of Chomsky 1959, researchers have shifted their ultimate focus from overt behavior - the analog of "E-language" - to the underlying cognitive structures - a broad set including "I-language" as an instance. Most have seen this as a significant conceptual advance, and one that did not take "behavioral biology" out of the larger realm 
of biology. Everett's (and Postal's) position would effectively undo this progress, for reasons that seem to us nothing but matters of terminological preconception.

In conclusion, we do not feel that Everett's observations, to the extent they are actually based on analyses or positions to be found in our book, compromise the biological program set out there for the study of language or the productivity of the proposal that the human language faculty can be usefully regarded as an organ - in the functional, physiological sense and not the anatomical. The point of our book was to explain this perspective to our colleagues in other fields, and we continue to hope that they may enlarge their understanding of the object of inquiry in linguistics by reading it.

\section{References}

Anderson, Stephen R. 2005. Aspects of the theory of clitics. Oxford: Oxford University Press.

Anderson, Stephen R. In Press. Review of Christansen \& Kirby 2003. Language .

Anderson, Stephen R. \& David W. Lightfoot. 1999. The human language faculty as an organ. Annual Review of Physiology 62. 697-722.

Anderson, Stephen R. \& David W. Lightfoot. 2002. The language organ: Linguistics as cognitive physiology. Cambridge: Cambridge University press.

Chomsky, Noam. 1959. Review of B. F. Skinner, Verbal Behavior. Language 35. 547-578.

Christansen, Morton H. \& Simon Kirby, eds. 2003. Language evolution. Oxford: Oxford University Press.

Everett, Daniel L. 2001. Discussion: On nonobjects of linguistic study. Linguist List, volume 12, number 1816.

Everett, Daniel L. 2005. Biology and language: a consideration of alternatives. Journal of Linguistics 41. 157-175.

Fitch, W. Tecumseh, Marc D. Hauser \& Noam Chomsky. 2005. The evolution of the language faculty: Clarifications and implications. Cognition. in press.

Givón, Talmy. 2002. Biolinguistics: The Santa Barbara lectures. Amsterdam: John Benjamins.

Hauser, Marc D., Noam Chomsky \& W. Tecumseh Fitch. 2002. The faculty of language: What is it, who has it, and how did it evolve? Science 298. 1569-1579.

Lightfoot, David W. 1999. The development of language: Acquisition, change and evolution. Oxford: Blackwell.

Pinker, Steven \& Ray Jackendoff. 2005. The faculty of language: What's special about it? Cognition. in press.

Postal, Paul. 2004. Skeptical linguistic essays. Oxford: Oxford University Press.

Pullum, Geoffrey K. \& Barbara C. Scholz. 2002. Empirical assessment of stimulus poverty arguments. The Linguistic Review 19. 9-50. 
Pulvermüller, Friedman. 2002. The neuroscience of language: On brain circuits of words and serial order. Cambridge: Cambridge University Press.

\section{Notes}

* This material is based upon work supported while Lightfoot was serving at the National Science Foundation. Any opinion and conclusions are those of the authors and do not necessarily reflect the views of the National Science Foundation. 